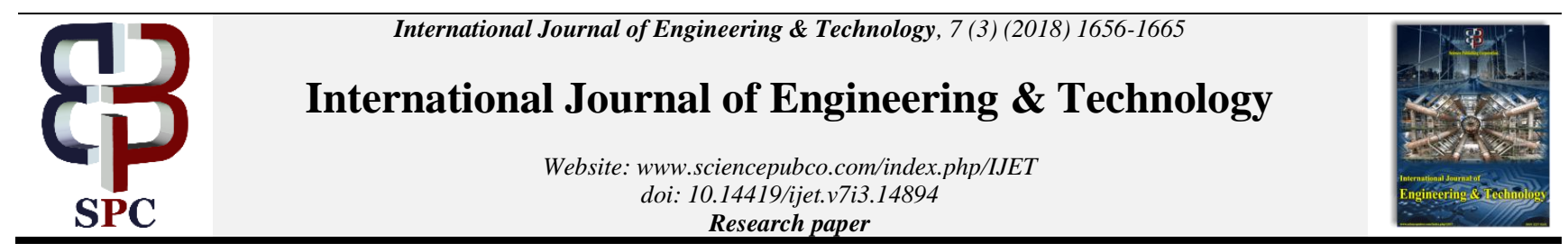

\title{
Interline power flow controller (IPFC) characterization in power systems
}

\author{
Nabil A. Hussein ${ }^{1 *}$, Ayman A. Eisa ${ }^{2}$, Hassan M. Mahmoud ${ }^{3}$, Safy A. Shehata ${ }^{1}$, El-Saeed A. Othman ${ }^{4}$ \\ ${ }^{1}$ Nuclear Research Center, Egypt Atomic Energy Authority (EAEA), Egypt \\ ${ }^{2}$ National Center for Radiation Research and Technology, EAEA, Egypt \\ ${ }^{3}$ Ministry of Electricity and Renewable Energy (MOEE), Egypt \\ ${ }^{4}$ Dept. of electrical engineering, Faculty of Engineering, Al-Azhar University, Egypt \\ *Corresponding author E-mail:Nabil_Ahmed.eaea@yahoo.com
}

\begin{abstract}
Flexible AC Transmission Systems (FACTS) have been proposed in the late 1980s to meet and provide the electrical power system requirements. FACTS are used to control the power flow and to improve the power system stability. Interline power flow controller (IPFC) is a versatile device in the FACTS family of controllers and one of its latest generations which has the ability to simultaneously control the power flow in two or multiple transmission lines. This paper is tackling the IPFC performance in power systems; it aims to discuss the availability to define a known scenario for the IPFC performance in different systems. An introduction supported with brief review on IPFC, IPFC principle of operation and IPFC mathematical model are also introduced. IEEE 14-bus and 30-bus systems have chosen as a test power systems to support the behavior study of power system equipped with IPFC device. Three different locations have chosen to give variety of system configurations to give effective performance analysis.
\end{abstract}

Keywords:Flexible AC Transmission Systems; Interline Power Flow Controller; Power Flow; Performance Analysis.

\section{Introduction}

IPFC was mainly proposed in 1998 to control both real and reactive power flow in the lines and thereby maximize the utilization of the transmission system [1]. In June 2007, IPFC was described as a VSC-based FACTS controller for series compensation with the unique capability for power management between multi-lines of a substation [2]. FACTSwas firstly proposed in the electric power research institute (EPRI) Journal in 1986 to mitigate the problems induced by the earlier technology in an existing power system [3]. In its general form, the IPFC employs a number of dcto-ac converters connected in series with number of transmission lines through series coupling transformers [4]. Each converter provides series compensation for a certain line. The dc terminals of the converters are connected together via a common dc link as shown in Fig. 1.With this IPFC, in addition to providing series reactive compensation, any converter can be controlled to supply real power to the common dc link from its own transmission line [5], [6].

The system configuration shown in Fig. 1 highlight the advantage of IPFC over classical active power filters like UPFC and UPQC as it compromises a smaller no of converters. This advantage has been tackled by R. Strzelecki, and G. Benysek in 2010 [8]. A comparison paper of applying UPFC and IPFC in power transmission systems was introduced in 2011; the author concluded that the IPFC is very effective FACTS device in the modern power system network [9].

In the steady state analysis of power systems, the dc-to-ac converters may be represented as a synchronous voltage source injecting an almost sinusoidal controllable voltage (magnitude and phase angle) as shown in Fig. 2 [10].

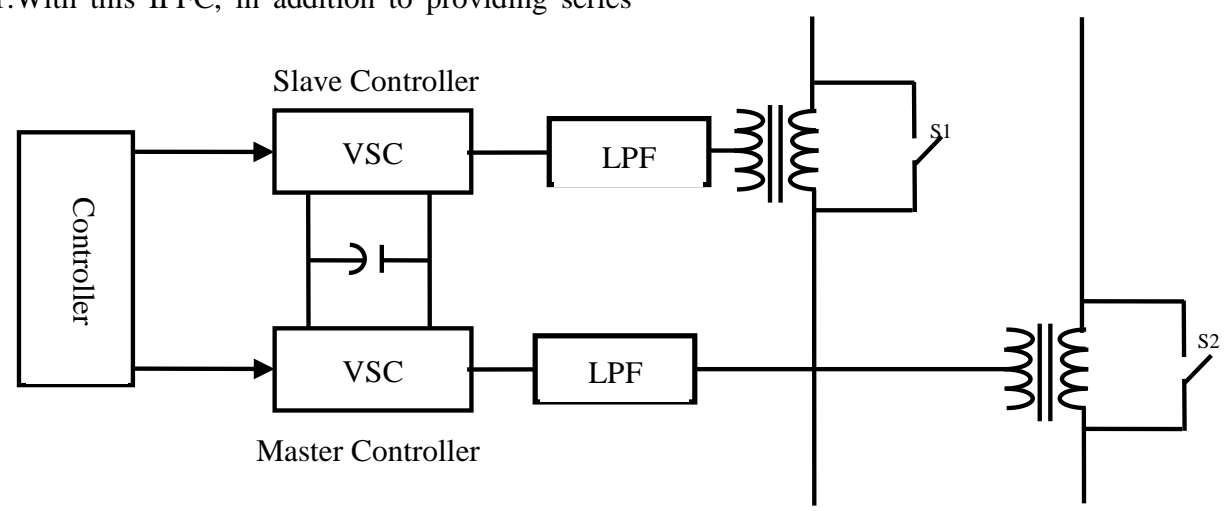

Fig. 1: Schematic of an IPFC [7]. 
K

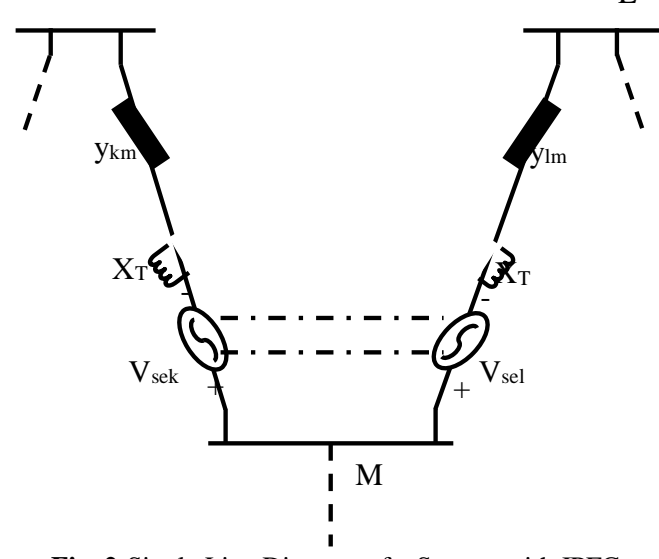

Fig. 2:Single Line Diagram of a System with IPFC.

IPFC power injected model (PIM) was proposed in 2006 by Yan Zhang and Chen incorporated in Newton-Raphsonmethod [4], this model has been applied by A.V.NareshBabu et al (2010) and by Natália M. R. Santos, O. P. Dias and V. FernãoPires (2011) to study the power flow control using IPFC in transmission lines [5,11]. References [12-15] are witness that the IPFC performance study is still area of interest to the engineering community. Understanding the device behavior is very important for designer as soon as for users, so that not only the theoretical principle of operation but also simulation modeling and testing case studies is in troduced in this paper. The case studies introduced gives a variety of system configurations to support the behavior analysis of power system equipped with IPFC. The availability of giving scenarios for IPFC behavior in known system configuration is clearly discussed in this paper.

\section{IPFC principle of operation}

The elementary IPFC scheme consisting of two back-to-back dcto-ac inverters each compensates a transmission line by series voltage injection is shown in Fig. 2-7. Two synchronous voltage sources (Vsek and Vsel) in series with transmission lines 1 and 2 respectively represent the two back-to-back dc-to-ac inverters [16]. The common dc link is represented by a bidirectional link for real power exchange between the two voltage sources. Transmission line 1 , represented by reactance $\mathrm{Xkm}$ (the equivalent reactance of XT and Ykm), has sending end bus voltage Vk. The sending end voltage of line 2, represented by reactance $\mathrm{Xlm}$, is $\mathrm{Vl}$ and the receiving end voltage for both lines is $\mathrm{Vm}[2]$.

In order to establish the relationships between the two systems, system 1 is arbitrarily selected to be the master system for which free controllability of both real and reactive line power flow is possible. The free controllability of system 1 is considered as the constraint imposed upon the power flow control of system 2 .

A phasor diagram of system 1 , defining the relationship between $\mathrm{Vk}, \mathrm{Vm}, \mathrm{Vkm}$ (the voltage phasor across $\mathrm{Xkm}$ ) and the injected voltage phasor Vsek, with controllable magnitude $(0 \leq$ Vsek $\leq$ Vsekmax) and angle $\left(0 \leq \delta\right.$ sek $\left.\leq 360^{\circ}\right)$ is shown in Fig. 3. As can be seenVk is considered as the reference vector.

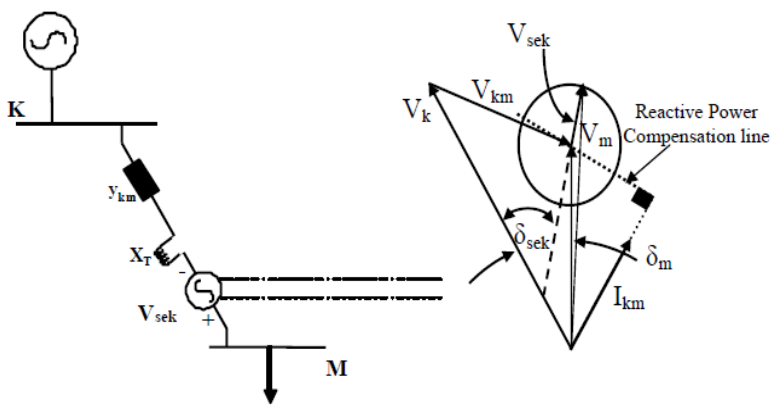

Fig. 3:IPFC's Master Converter and Corresponding Phasor Diagram [16].
The real power produced by the series voltage insertion is obtained from the other line via the series-connected compensating converter of that line. In order to establish the possible compensation range for slave line (line 2), under the constraints imposed by the unrestricted compensation of master line (line 1), it is helpful to decompose the overall compensating power provided for master line into reactive power Qsek and real power Psek. The component Qsek provides series reactive compensation for master line. The component Psek provides real power compensation for master line, but this power must be supplied from the slave line.

The series injected power in the master line is the outcome of multiplying the series injected voltage Vsek with the line current Ikm. If Vsek is perpendicular to Ikm, then the produced power will be only the reactive component. So that the line in the compensation circle that is perpendicular to the line current is called the reactive power compensation line as shown in Fig. 3. The real power demand is, by definition, zero when the trajectory of Vsek coincides with the reactive power compensation line, which divides the circular operating region into two equal halves. An increasing amount of real power is to be supplied to the system above the reactive power compensation line in the upper half of the control region. Conversely, increasing real power is to be absorbed from the system below the reactive power compensation line in the lower half of the compensation region [17].

Buses K, L, and M could be swing bus, PV buses or PQ Buses. For a given system, there is only one swing bus, and it can be designatedby the engineer to be any bus connected to a generator in the system. For the swing bus, voltage magnitude $(|\mathrm{V}|)$ and angle $(\delta)$ are known quantities. Two other common terms for this bus are slack bus and reference bus.PV buses whichcalled generator buses fall under the category of voltage-controlled buses because of the ability to specify the voltage magnitude of this bus. For PV-Bus $\mathrm{P}$ and $|\mathrm{V}|$ are known quantities. The real power is chosen according to the system dispatch corresponding to the modeled loading conditions. The voltage magnitude is chosen according to the expected terminal voltage settings.PQ Buses (load buses) which are connected to a load. They are also including buses that have neither load nor generation. For PQ-Bus $\mathrm{P}$ and $\mathrm{Q}$ are known quantities. The real power is chosen according to the loading conditions being modeled. The reactive power is chosen according to the expected power factor of the load [18].

\section{Mathematical model}

Considering the NR method then:

$\left[\begin{array}{c}\mathrm{f}_{\mathrm{P}} \\ \mathrm{f}_{\mathrm{Q}} \\ \mathrm{f}_{\mathrm{ipfc}}\end{array}\right]=\left[\begin{array}{ccc}\frac{\partial \mathrm{P}}{\partial \delta} & \frac{\partial \mathrm{P}}{\partial \mathrm{V}} & \frac{\partial \mathrm{P}}{\partial \mathrm{ipfc}} \\ \frac{\partial \mathrm{Q}}{\partial \delta} & \frac{\partial \mathrm{Q}}{\partial \mathrm{V}} & \frac{\partial \mathrm{Q}}{\partial \mathrm{ipfc}} \\ \frac{\partial \mathrm{f}_{\text {ipfc }}}{\partial \delta} & \frac{\partial \mathrm{f}_{\text {ipfc }}}{\partial \mathrm{V}} & \frac{\partial \mathrm{f}_{\text {ipfc }}}{\partial \mathrm{ipfc}}\end{array}\right]\left[\begin{array}{c}\Delta \delta \\ \Delta \mathrm{V} \\ \Delta \mathrm{ipfc}\end{array}\right]$

The Jacobian matrix $\mathrm{J}$ can be formed as:

$J=\left[\begin{array}{lll}J_{1} & J_{2} & J_{5} \\ J_{3} & J_{4} & J_{6} \\ J_{6} & J_{8}\end{array}\right]$

Where:

$$
\begin{array}{r}
P_{i}=\sum_{j=1}^{N} V_{i} V_{j} Y_{i j} \cos \left(\theta_{i j}+\delta_{j}-\delta_{i}\right) \\
, Q_{i}=-\sum_{j=1}^{N} V_{i} V_{j} Y_{i j} \sin \left(\theta_{i j}+\delta_{j}-\delta_{i}\right)
\end{array}
$$




$$
\begin{aligned}
\mathrm{J}_{1}=\frac{\partial \mathrm{P}}{\partial \delta}, \mathrm{J}_{2}=\frac{\partial \mathrm{P}}{\partial \mathrm{V}}, \mathrm{J}_{3} & =\frac{\partial \mathrm{Q}}{\partial \delta}, \mathrm{J}_{4}=\frac{\partial \mathrm{Q}}{\partial \mathrm{V}}, \mathrm{J}_{5}=\left[\begin{array}{c}
\frac{\partial \mathrm{P}}{\partial \mathrm{ipfc}} \\
\frac{\partial \mathrm{Q}}{\partial \mathrm{ipfc}}
\end{array}\right], \mathrm{J}_{6}=\frac{\partial \mathrm{f}_{\mathrm{ipfc}}}{\partial \delta}, \mathrm{J}_{7} \\
& =\frac{\partial \mathrm{f}_{\mathrm{ipfc}}}{\partial \mathrm{V}}, \mathrm{J}_{8}=\frac{\partial \mathrm{f}_{\mathrm{ipfc}}}{\partial \mathrm{ipfc}} \\
\mathrm{f}_{\text {ipfc }} & =\left[\begin{array}{c}
\mathrm{P}_{\mathrm{d} 1} \\
\mathrm{P}_{\mathrm{se}} \\
\mathrm{Q}_{\mathrm{d} 1} \\
\mathrm{Q}_{\mathrm{d} 2}
\end{array}\right], \Delta \mathrm{ipfc}=\left[\begin{array}{c}
\Delta \delta_{\mathrm{se}_{\mathrm{k}}} \\
\Delta \delta_{\mathrm{se}_{1}} \\
\Delta \mathrm{V}_{\mathrm{se}_{\mathrm{k}}} \\
\Delta \mathrm{V}_{\mathrm{se}_{1}}
\end{array}\right]
\end{aligned}
$$

While for each bus $\mathrm{V}$ is the voltage magnitude, $\delta$ is the phase angle, $\mathrm{P}$ is the real power, and $\mathrm{Q}$ is the reactive power. $\mathrm{Pd} 1$ is the $1 \mathrm{st}$ line active power flow, $\mathrm{Qd} 1$ and $\mathrm{Qd} 2$ are the reactive power flows in both lines and $\mathrm{P}_{\text {se }_{\text {net }}}$ is the total injected active power, it supposed to be zero based on the idea of maintaining constant common DC link and no active power source i.e. $\mathrm{P}_{\text {se }_{\text {net }}}=0$.

As insertion of the IPFC changes the active and reactive power function at the related busses $(\mathrm{K}, \mathrm{L}$ and $\mathrm{M})$ according to the relations; $\left(P_{\text {inew }}=P_{i}+P_{i n j_{j}}, Q_{\text {inew }}=Q_{i}+Q_{i n j_{i}}\right)$, this change affects the main Jacobian matrix as follow

For J1:

$\frac{\partial \mathrm{P}_{\text {inew }}}{\partial \delta_{\mathrm{i}}}=\frac{\partial \mathrm{P}_{\mathrm{i}}}{\partial \delta_{\mathrm{i}}}+\frac{\partial \mathrm{P}_{\mathrm{inj}_{\mathrm{i}}}}{\partial \delta_{\mathrm{i}}}$

$\frac{\partial \mathrm{P}_{\mathrm{inj}_{\mathrm{i}}}}{\partial \delta_{\mathrm{i}}}=-\mathrm{V}_{\mathrm{i}} \mathrm{V}_{\mathrm{se}_{\mathrm{i}}} \mathrm{Y}_{\mathrm{im}} \sin \left(\theta_{\mathrm{im}}+\delta_{\mathrm{se}_{\mathrm{i}}}-\delta_{\mathrm{i}}\right), \mathrm{i}=\mathrm{k}, \mathrm{l}$

$\frac{\partial \mathrm{P}_{\mathrm{inj}_{\mathrm{m}}}}{\partial \delta_{\mathrm{m}}}=\sum_{\mathrm{i}=\mathrm{k}, \mathrm{l}} \mathrm{V}_{\mathrm{m}} \mathrm{V}_{\mathrm{se}_{\mathrm{i}}} \mathrm{Y}_{\mathrm{im}} \sin \left(\theta_{\mathrm{im}_{\mathrm{m}}}+\delta_{\mathrm{se}_{\mathrm{i}}}-\delta_{\mathrm{m}}\right)$

For J2:

$\frac{\partial \mathrm{P}_{\text {inew }}}{\partial \mathrm{V}_{\mathrm{i}}}=\frac{\partial \mathrm{P}_{\mathrm{i}}}{\partial \mathrm{V}_{\mathrm{i}}}+\frac{\partial \mathrm{P}_{\text {inj }_{\mathrm{i}}}}{\partial \mathrm{V}_{\mathrm{i}}}$

$\frac{\partial \mathrm{P}_{\mathrm{inj}_{\mathrm{i}}}}{\partial \mathrm{V}_{\mathrm{i}}}=-\mathrm{V}_{\mathrm{se}_{\mathrm{i}}} \mathrm{Y}_{\mathrm{im}} \cos \left(\theta_{\mathrm{im}}+\delta_{\mathrm{se}_{\mathrm{i}}}-\delta_{\mathrm{i}}\right), \mathrm{i}=\mathrm{k}, \mathrm{l}$

$\frac{\partial P_{i n j_{m}}}{\partial V_{m}}=\sum_{i=k, l} V_{s e_{i}} Y_{i m} \cos \left(\theta_{i m}+\delta_{s e_{i}}-\delta_{m}\right)$

For J3:

$$
\frac{\partial Q_{\text {inew }}}{\partial \delta_{i}}=\frac{\partial Q_{i}}{\partial \delta_{i}}+\frac{\partial Q_{\text {inj }}}{\partial \delta_{i}}
$$

$\frac{\partial Q_{i n j_{i}}}{\partial \delta_{i}}=-V_{i} V_{s e_{i}} Y_{i m} \cos \left(\theta_{i m}+\delta_{s e_{i}}-\delta_{i}\right), i=k, l$

$\frac{\partial Q_{i n j m}}{\partial \delta_{m}}=\sum_{i=k, l} V_{m} V_{s e_{i}} Y_{i m} \cos \left(\theta_{i m}+\delta_{s e_{i}}-\delta_{m}\right)$

For J4:

$$
\begin{aligned}
& \frac{\partial Q_{\text {inew }}}{\partial V_{i}}=\frac{\partial Q_{i}}{\partial V_{i}}+\frac{\partial Q_{i n j_{i}}}{\partial V_{i}} \\
& \frac{\partial Q_{i n j_{i}}}{\partial V_{i}}=V_{s e_{i}} Y_{i m} \sin \left(\theta_{i m}+\delta_{s e_{i}}-\delta_{i}\right), i=k, l \\
& \frac{\partial Q_{i n j_{m}}}{\partial V_{m}}=-\sum_{i=k, l} V_{s e_{i}} Y_{i m} \sin \left(\theta_{i m}+\delta_{s e_{i}}-\delta_{m}\right)
\end{aligned}
$$

The added elements in the Jacobian matrix due to presence of the IPFC device expressed as J5, J6, J7 and J8

The added elements in the Jacobian matrix due to presence of the IPFC device expressed as J5, J6, J7 and J8 For J5:
The equation $J_{5}=\left[\begin{array}{c}\frac{\partial P}{\partial i p f c} \\ \frac{\partial Q}{\partial i p f c}\end{array}\right]$ consists of the following elements:

$\frac{\partial P_{i}}{\partial \delta_{s e_{i}}}=V_{i} V_{s e_{i}} Y_{i m} \sin \left(\theta_{i m}+\delta_{s e_{i}}-\delta_{i}\right), i=k, l$

$\frac{\partial P_{m}}{\partial \delta_{s e_{i}}}=-V_{m} V_{s e_{i}} Y_{i m} \sin \left(\theta_{i m}+\delta_{s e_{i}}-\delta_{m}\right), i=k, l$

$\frac{\partial P_{i}}{\partial V_{s e_{i}}}=-V_{i} Y_{i m} \cos \left(\theta_{i m}+\delta_{s e_{i}}-\delta_{i}\right), i=k, l$

$\frac{\partial P_{m}}{\partial V_{s e_{i}}}=V_{m} Y_{i m} \cos \left(\theta_{i m}+\delta_{s e_{i}}-\delta_{m}\right), i=k, l$

$\frac{\partial Q_{i}}{\partial \delta_{s e_{i}}}=V_{i} V_{s e_{i}} Y_{i m} \cos \left(\theta_{i m}+\delta_{s e_{i}}-\delta_{i}\right), i=k, l$

$\frac{\partial Q_{m}}{\partial \delta_{s e_{i}}}=-V_{m} V_{s e_{i}} Y_{i m} \cos \left(\theta_{i m}+\delta_{s e_{i}}-\delta_{m}\right), i=k, l$

$\frac{\partial Q_{i}}{\partial V_{s e_{i}}}=V_{i} Y_{i m} \sin \left(\theta_{i m}+\delta_{s e_{i}}-\delta_{i}\right), i=k, l$

$\frac{\partial Q_{m}}{\partial V_{s e_{i}}}=-V_{m} Y_{i m} \sin \left(\theta_{i m}+\delta_{s e_{i}}-\delta_{m}\right), i=k, l$

For J6:

The equation $J_{6}=\frac{\partial f_{i p f c}}{\partial \delta}$ consists of the following elements:

$\frac{\partial P_{d 1}}{\partial \delta_{k}}=V_{k} V_{m} Y_{k m} \sin \left(\theta_{k m}+\delta_{m}-\delta_{k}\right)-V_{k} V_{s e_{k}} Y_{k m} \sin \left(\theta_{k m}+\right.$

$\left.\delta_{s e_{k}}-\delta_{k}\right)$

$\frac{\partial P_{d 1}}{\partial \delta_{m}}=-V_{k} V_{m} Y_{k m} \sin \left(\theta_{k m}+\delta_{m}-\delta_{k}\right)$

$\frac{\partial P_{s e_{n e t}}}{\partial \delta_{i}}=-V_{i} V_{s e_{i}} Y_{i m} \sin \left(\theta_{i m}+\delta_{s e_{i}}-\delta_{i}\right), i=k, l$

$\frac{\partial P_{s e_{n e t}}}{\partial \delta_{m}}=\sum_{i=k, l} V_{m} V_{s e_{i}} Y_{i m} \sin \left(\theta_{i m}+\delta_{s e_{i}}-\delta_{m}\right)$

$\frac{\partial Q_{d 1}}{\partial \delta_{k}}=V_{k} V_{m} Y_{k m} \cos \left(\theta_{k m}+\delta_{m}-\delta_{k}\right)-V_{k} V_{s e_{k}} Y_{k m} \cos \left(\theta_{k m}+\right.$

$\left.\delta_{s e_{k}}-\delta_{k}\right)$

$\frac{\partial Q_{d 1}}{\partial \delta_{m}}=-V_{k} V_{m} Y_{k m} \cos \left(\theta_{k m}+\delta_{m}-\delta_{k}\right)$

$\frac{\partial Q_{d 2}}{\partial \delta_{l}}=V_{l} V_{m} Y_{l m} \cos \left(\theta_{l m}+\delta_{m}-\delta_{l}\right)-V_{l} V_{s e_{l}} Y_{l m} \cos \left(\theta_{l m}+\right.$

$\left.\delta_{s e_{l}}-\delta_{l}\right)$

$\frac{\partial Q_{d 2}}{\partial \delta_{m}}=-V_{l} V_{m} Y_{l m} \cos \left(\theta_{l m}+\delta_{m}-\delta_{l}\right)$

For J7:

The equation $J_{7}=\frac{\partial f_{i p f c}}{\partial V}$ consists of the following elements:

$\frac{\partial P_{d 1}}{\partial V_{k}}=-2 V_{k} Y_{k m} \cos \left(\theta_{k m}\right)+V_{m} Y_{k m} \cos \left(\theta_{k m}+\delta_{m}-\delta_{k}\right)-$

$V_{s e_{k}} Y_{k m} \cos \left(\theta_{k m}+\delta_{s e_{k}}-\delta_{k}\right)$

$\frac{\partial P_{d 1}}{\partial V_{m}}=V_{k} Y_{k m} \cos \left(\theta_{k m}+\delta_{m}-\delta_{k}\right)$

$\frac{\partial P_{s e_{n e t}}}{\partial V_{i}}=-V_{s e_{i}} Y_{i m} \cos \left(\theta_{i m}+\delta_{s e_{i}}-\delta_{i}\right), i=k, l$

$\frac{\partial P_{\text {senet }}}{\partial V_{m}}=\sum_{i=k, l} V_{s e_{i}} Y_{i m} \cos \left(\theta_{i m}+\delta_{s e_{i}}-\delta_{m}\right)$ 
$\frac{\partial Q_{d 1}}{\partial V_{k}}=2 V_{k} Y_{k m} \sin \left(\theta_{k m}\right)-V_{m} Y_{k m} \sin \left(\theta_{k m}+\delta_{m}-\delta_{k}\right)+$

$V_{s e_{k}} Y_{k m} \sin \left(\theta_{k m}+\delta_{s e_{k}}-\delta_{k}\right)$

$\frac{\partial Q_{d 1}}{\partial V_{m}}=-V_{k} Y_{k m} \sin \left(\theta_{k m}+\delta_{m}-\delta_{k}\right)$

$\frac{\partial Q_{d 2}}{\partial V_{l}}=2 V_{l} Y_{l m} \cos \left(\theta_{l m}+\delta_{m}-\delta_{l}\right)-V_{m} Y_{l m} \cos \left(\theta_{l m}+\delta_{m}-\right.$

$\left.\delta_{l}\right)+V_{s e_{l}} Y_{l m} \cos \left(\theta_{l m}+\delta_{s e_{l}}-\delta_{l}\right)$

$\frac{\partial Q_{d 2}}{\partial V_{m}}=-V_{l} Y_{l m} \sin \left(\theta_{l m}+\delta_{m}-\delta_{l}\right)$

For J8:

The equation $J_{8}=\frac{\partial f_{i p f c}}{\partial i p f c}$ consists of the following elements:

$\frac{\partial P_{d 1}}{\partial \delta_{s e_{k}}}=V_{k} V_{s e_{k}} Y_{k m} \sin \left(\theta_{k m}+\delta_{s e_{k}}-\delta_{k}\right)$

$\frac{\partial P_{s e_{n e t}}}{\partial \delta_{s e_{i}}}=V_{i} V_{s e_{i}} Y_{i m} \sin \left(\theta_{i m}+\delta_{s e_{i}}-\delta_{i}\right)-V_{m} V_{s e_{i}} Y_{i m} \sin \left(\theta_{i m}+\right.$

$\left.\delta_{s e_{i}}-\delta_{m}\right), i=k, l$

$\frac{\partial Q_{d 1}}{\partial \delta_{s e_{k}}}=V_{k} V_{s e_{k}} Y_{k m} \cos \left(\theta_{k m}+\delta_{s e_{k}}-\delta_{k}\right)$

$\frac{\partial Q_{d 2}}{\partial \delta_{s e_{1}}}=\mathrm{V}_{\mathrm{l}} \mathrm{V}_{\mathrm{se}_{\mathrm{l}}} \mathrm{Y}_{\mathrm{lm}} \cos \left(\theta_{\mathrm{lm}}+\delta_{\mathrm{se}_{\mathrm{l}}}-\delta_{\mathrm{l}}\right)$ $\frac{\partial \mathrm{P}_{\mathrm{d} 1}}{\partial \mathrm{V}_{\mathrm{se}_{\mathrm{k}}}}=-\mathrm{V}_{\mathrm{k}} \mathrm{Y}_{\mathrm{km}} \cos \left(\theta_{\mathrm{km}}+\delta_{\mathrm{se}_{\mathrm{k}}}-\delta_{\mathrm{k}}\right)$

$\frac{\partial \mathrm{P}_{\mathrm{se}_{\text {net }}}}{\partial \mathrm{V}_{\mathrm{se}_{\mathrm{i}}}}=-\mathrm{V}_{\mathrm{i}} \mathrm{Y}_{\mathrm{im}} \sin \left(\theta_{\mathrm{im}}+\delta_{\mathrm{se}_{\mathrm{i}}}-\delta_{\mathrm{i}}\right)+\mathrm{V}_{\mathrm{m}} \mathrm{Y}_{\mathrm{im}} \sin \left(\theta_{\mathrm{im}_{\mathrm{m}}}+\delta_{\mathrm{se}_{\mathrm{i}}}-\right.$

$\left.\delta_{\mathrm{m}}\right), \mathrm{i}=\mathrm{k}, \mathrm{l}$

$\frac{\partial \mathrm{Q}_{\mathrm{d} 1}}{\partial \mathrm{V}_{\mathrm{se}_{\mathrm{k}}}}=\mathrm{V}_{\mathrm{k}} \mathrm{Y}_{\mathrm{km}} \sin \left(\theta_{\mathrm{km}}+\delta_{\mathrm{se}_{\mathrm{k}}}-\delta_{\mathrm{k}}\right)$

$\frac{\partial \mathrm{Q}_{\mathrm{d} 2}}{\partial \mathrm{V}_{\mathrm{se}_{\mathrm{l}}}}=\mathrm{V}_{\mathrm{l}} \mathrm{Y}_{\mathrm{lm}} \sin \left(\theta_{\mathrm{lm}}+\delta_{\mathrm{se}_{1}}-\delta_{\mathrm{l}}\right)$

\section{Case studies}

Based on the bus type, three system configurations from two different power systems have been chosen to be the case studies, these two systems are standard IEEE 14-bus and IEEE 30-bus systems. For all the cases, the convergence tolerance is $1 \mathrm{e}-5 \mathrm{pu}$. IEEE 14-Bus system: This test system is shown in Fig. 4.Bus 1 is considered as the swing bus, while bus 2, 3, 6 and 8 are PV buses while the other buses are PQ buses. The system base MVA is 100. IEEE 30-Bus system: This test system is shown in Fig. 5.Bus 1 is considered as the swing bus, while bus $2,5,8,11$ and 13 are PV buses while the other buses are PQ buses. The system base MVA is 100 .

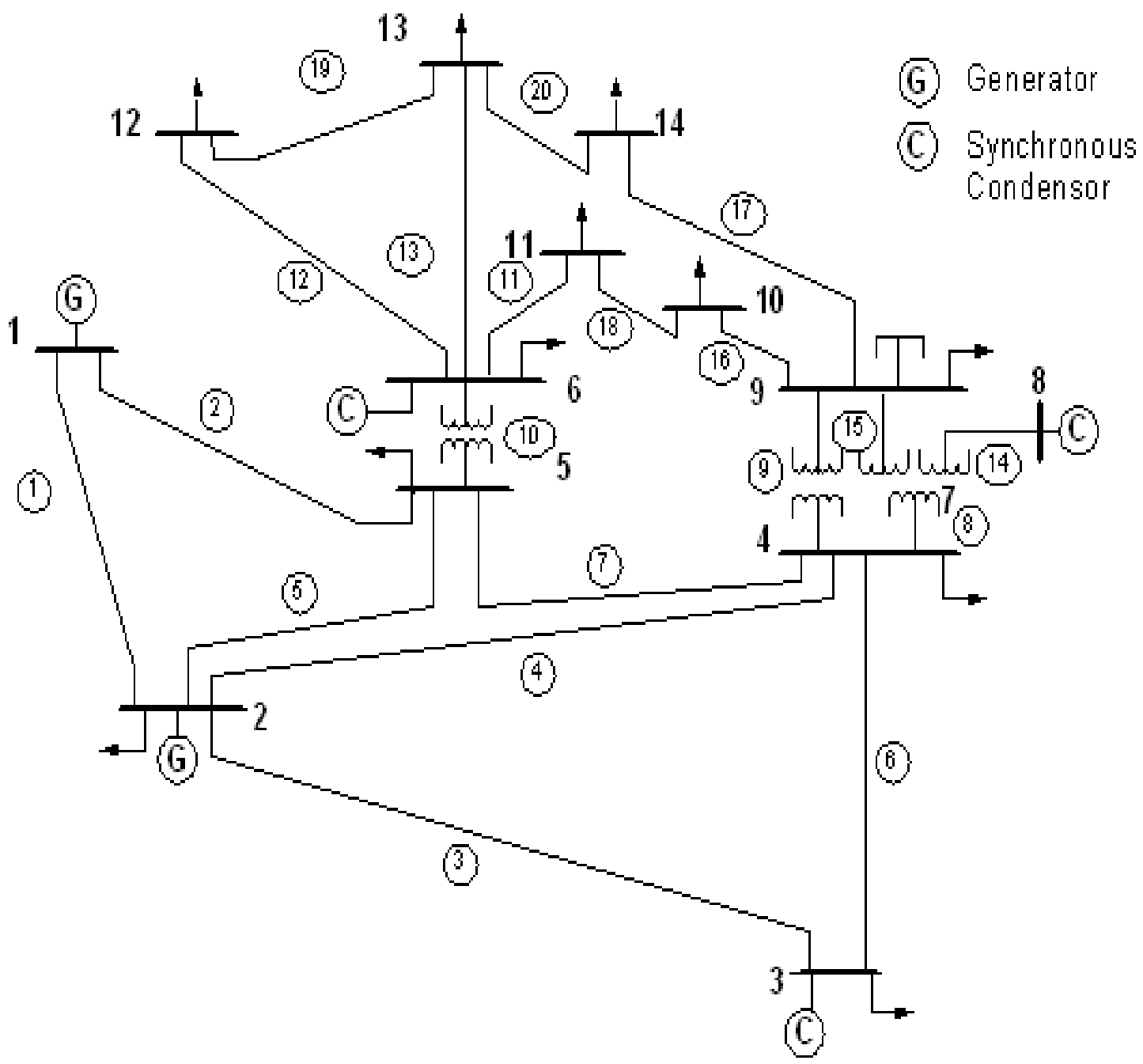

Fig.4: IEEE 14-Bus System. 


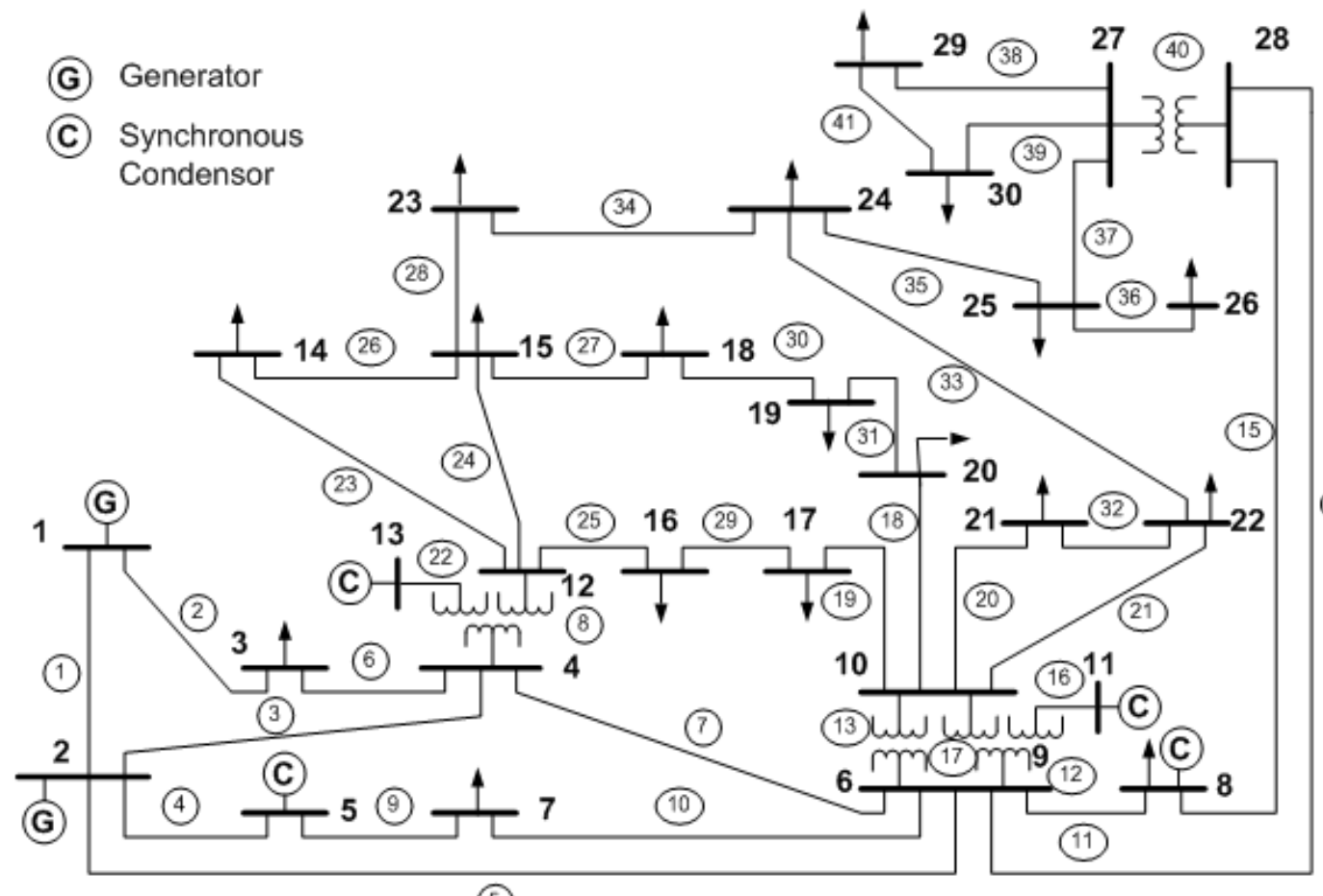

Fig.5: IEEE 30-Bus System.

\subsection{Case 1}

In this case, the IPFC common bus is PQ bus which fed from two buses via the master and slave lines, these two buses are PQ and PV. For the 30-Bus system: the IPFC lines have been chosen randomly to be 3 and 6; the series coupling transformer impedance $\mathrm{Xt}$, is $0.8 \mathrm{pu}$; the master line active and reactive power flow values for the system without IPFC are 0.4361 and 0.04952 in pu respectively; the slave line reactive power flow values for the system without IPFC is -0.03978 pu.For the 14-Bus system: the IPFC lines have been chosen randomly to be 5 and 7 ; the series coupling transformer impedance is $2 \mathrm{pu}$; the master line active and reactive power flow values for the system without IPFC are 0.431534 and 0.03299 in pu respectively; the slave line reactive power flow values for the system without IPFC is $0.14853 \mathrm{pu}$.

\subsection{Case 2}

In this case, the IPFC common bus is PQ bus which fed from two buses via the master and slave lines, these two buses are also PQ. For the 30-Bus system: the IPFC lines have been chosen randomly to be 34 and 35; the series coupling transformer impedance is $1 \mathrm{pu}$; the master line active and reactive power flow values for the system without IPFC are 0.01806 and 0.0015 in pu respectively; the slave line reactive power flow values for the system without IPFC is -0.02373 pu.For the 14-Bus system: the IPFC lines have been chosen randomly to be 19 and 20; the series coupling transformer impedance is $0.1 \mathrm{pu}$; the master line active and reactive power flow values for the system without IPFC are 0.01639 and 0.00817 in pu respectively; the slave line reactive power flow values for the system without IPFC is $-0.01953 \mathrm{pu}$.

\subsection{Case 3}

In this case, the IPFC common bus is PV bus which fed from two buses via the master and slave lines, these two buses are PQ and PV. For the 30-Bus system: the IPFC lines have been chosen randomly to be 4 and 9; the series coupling transformer impedance is $0.5 \mathrm{pu}$; the master line active and reactive power flow values for the system without IPFC are 0.82262 and 0.04035 in pu respectively; the slave line reactive power flow values for the system without IPFC is -0.11168 pu.For the $14-B u s$ system: the IPFC lines have been chosen randomly to be 3 and 6 ; the series coupling transformer impedance is $0.001 \mathrm{pu}$; the master line active and reactive power flow values for the system without IPFC are 0.73268 and 0.05949 in pu respectively; the slave line reactive power flow values for the system without IPFC is $-0.04629 \mathrm{pu}$.

\section{Results and discussion}

For the described three cases, power system active and reactive power losses (Ploss, Qloss) in addition with the common bus voltage (V common bus) performance is considered with the change in the master line active and reactive power flow (pd master line, qd master line) and in the slave line reactive power flow (pd slave line). The left $\mathrm{Y}$-axis is assigned for the 30-Bus system and the right $\mathrm{Y}$-axis is assigned for the 14-Bus system.

\subsection{Case 1}

Figs 6-a,b and c show the impact of changing the master line active power flow, in $(\%)$ of its value for the power system without installing IPFC device, on the power system losses (active and reactive) and the IPFC common bus voltage.

(A)

\section{Ploss}

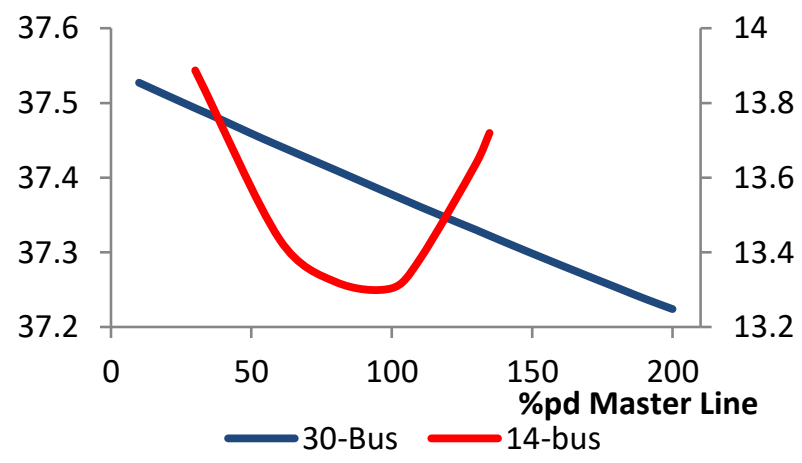


(B)

\section{Qloss}

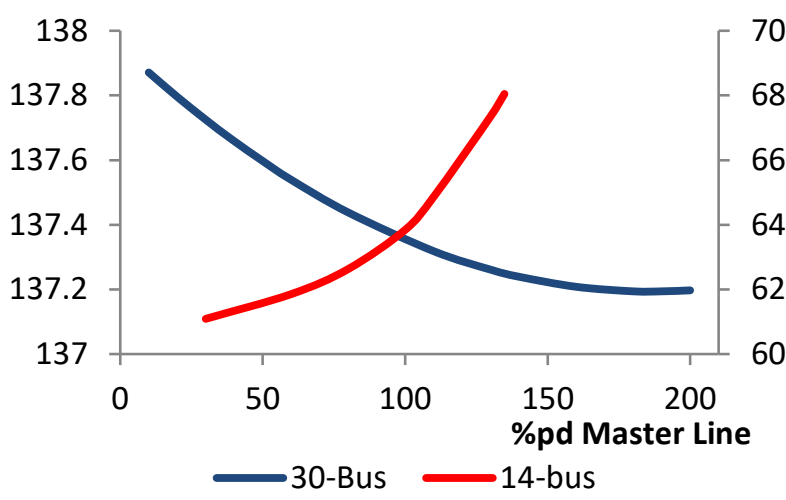

(C)

\section{V common bus}

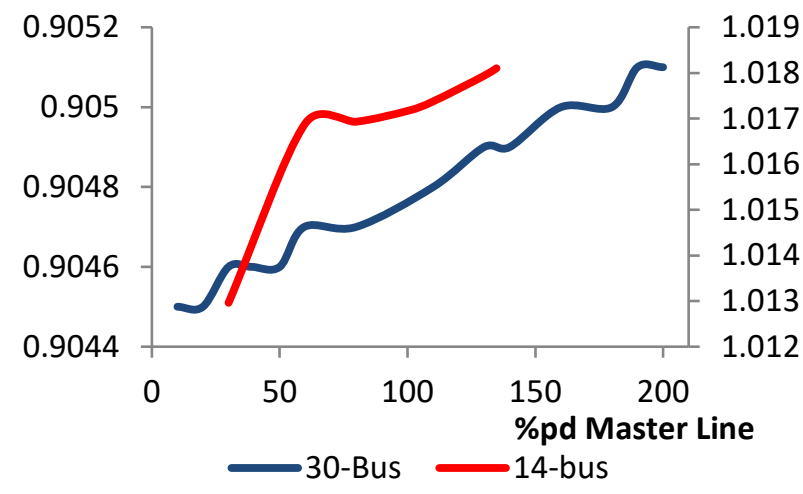

Fig. 6:Case1 Impact of Changing Master Line Pd On A) Active Power Loss (Ploss),B) Reactive Power Loss (Qloss) and C) IPFC Common Bus Voltage.

Fig. 6-a shows that the active power loss is linearly decreased with the increase of pd for the 30-Bus system however it performed as square equation regarding the 14-Bus system. In Fig. 6-b, it is shown that the reactive power loss has recorded exponential decrease with the increase in master line pd for the 30-Bus system but regarding the 14-Bus system exponential increase have been recorded. Either in the 30-Bus system or in the 14-Bus system the common bus voltage has gradually increased.

Figs 7-a, b and $\mathrm{c}$ show the impact of changing the master line reactive power flow, in (\%) of its value for the power system without installing IPFC device, on the power system losses (active and reactive) and the IPFC common bus voltage.

(A)

\section{Ploss}

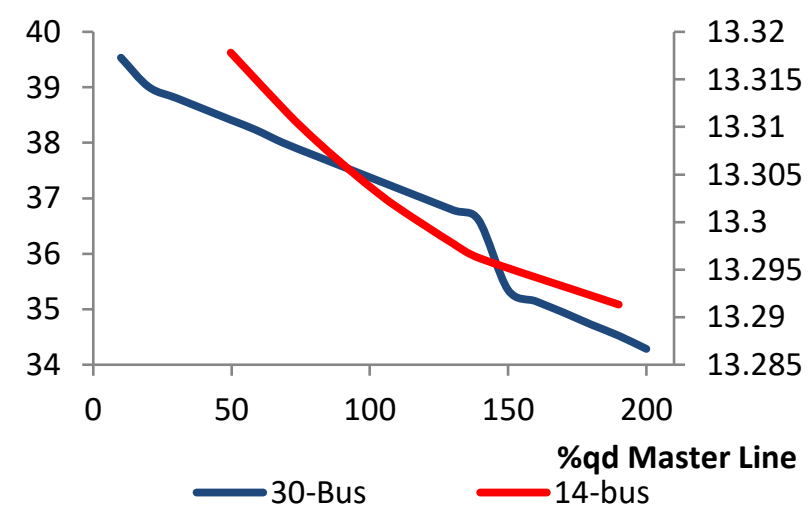

(B)

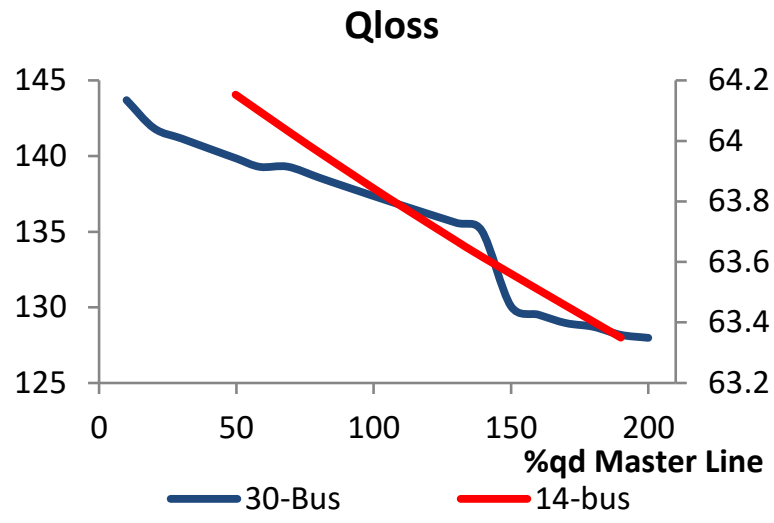

(C)

\section{V common bus}

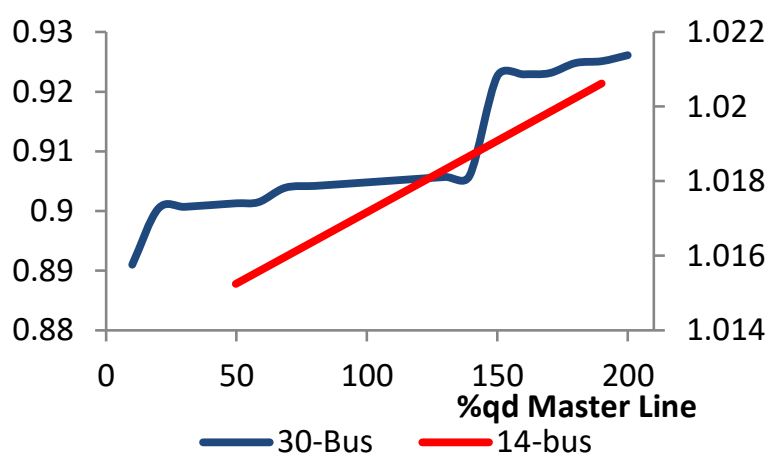

Fig. 7:Case 1 Impact of Changing Master Line Qd on A) Active Power Loss (Ploss), B) Reactive Power Loss (Qloss) and C) IPFC Common Bus Voltage.

The impact of changing master line qd in that case does not change with the change of power system as shown in Fig. 7. For both 30-Bus system and 14-Bus system, the active and reactive power losses are gradually decreased and the common bus voltage is increasing with the increase of master line qd.

Fig.s 8-a, b and c show the impact of changing the slave line reactive power flow, in (\%) of its value for the power system without installing IPFC device, on the power system losses (active and reactive) and the IPFC common bus voltage. In Fig. 8-a the active power loss has decreased then increased with the change of slave line qd at the 14-Bus system however it has just increased for the 30-Bus system. Fig. 8-b shows that the reactive power loss has increased in both 30-Bus and 14-Bus systems with the increase in slave line qd. Slave line qd increase causes increase followed by decrease in the common bus voltage for 14-Bus system but just decrease has been observed for the 30-Bus system.

(A)

\section{Ploss}

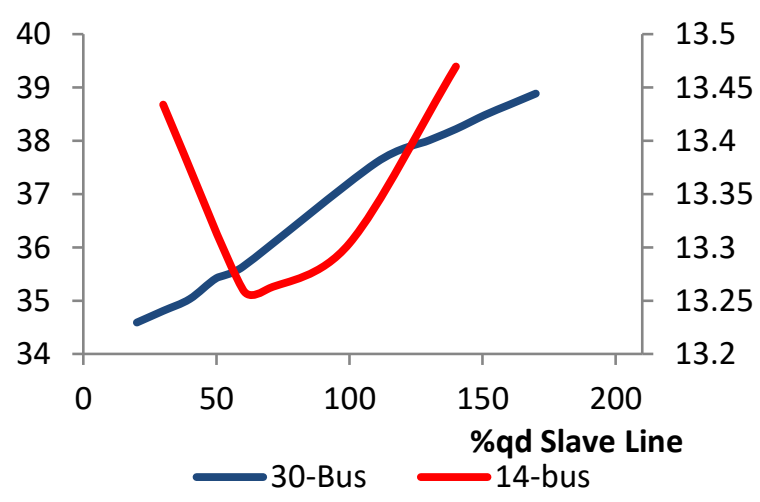


(B)

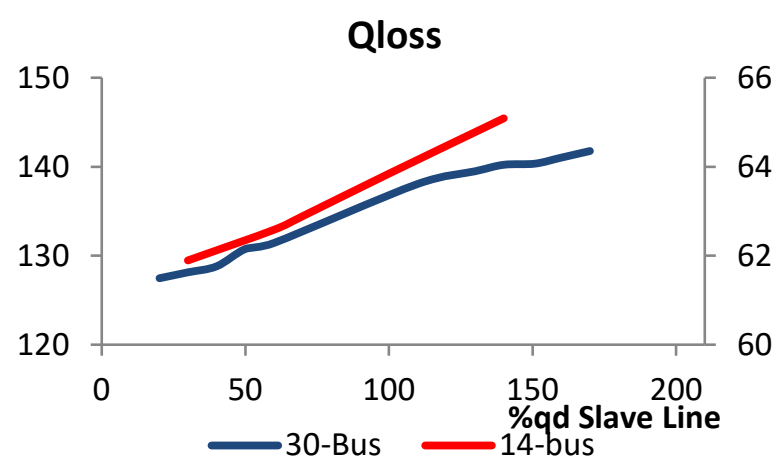

(C)

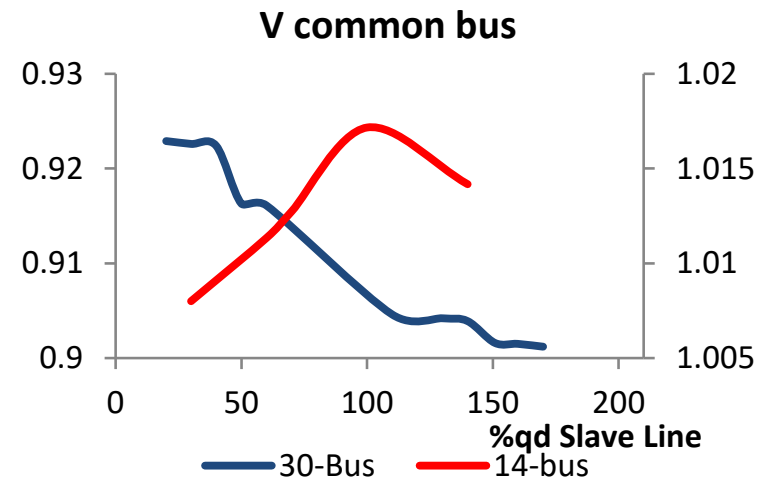

Fig. 8:Case 1 Impact of Changing Slave Line Qd on A) Active Power Loss (Ploss), B) Reactive Power Loss (Qloss) and C) IPFC Common Bus Voltage.

\subsection{Case 2}

Figs $9-\mathrm{a}, \mathrm{b}$ and $\mathrm{c}$ show the impact of changing the master line active power flow, in (\%) of its value for the power system without installing IPFC device, on the power system losses (active and reactive) and the IPFC common bus voltage.

(A)

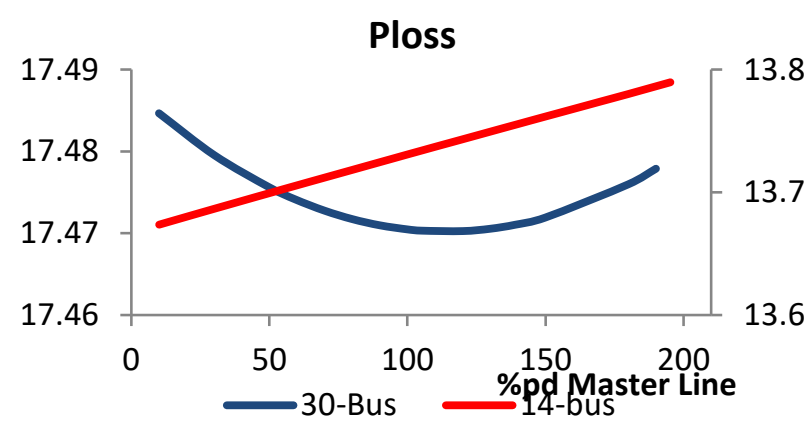

(B)

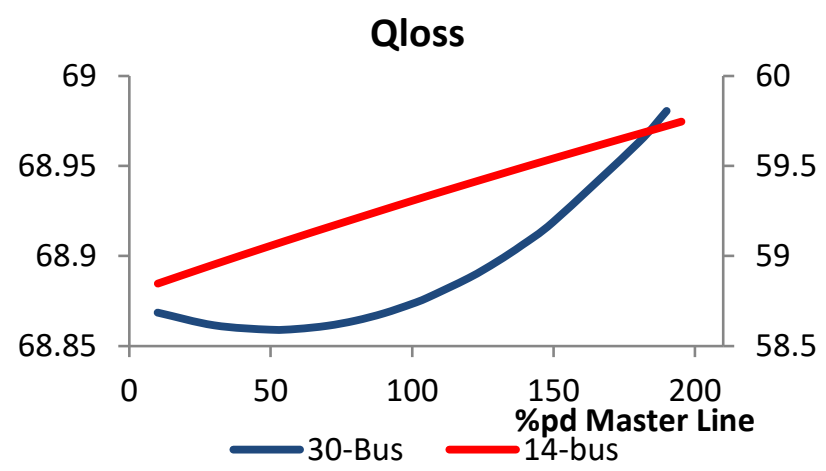

(C)

\section{V common bus}

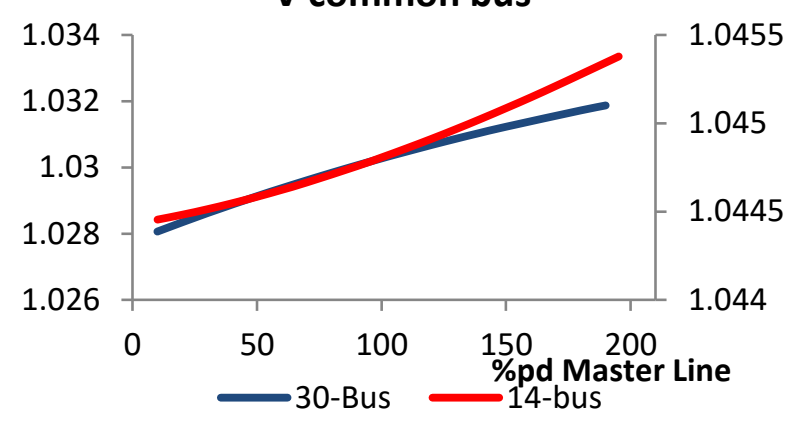

Fig. 9:Case 2 Impact of Changing Master Line Pd on A) Active Power Loss (Ploss), B) Reactive Power Loss (Qloss) and C) IPFC Common Bus Voltage.

Figs $10-\mathrm{a}, \mathrm{b}$ and $\mathrm{c}$ show the impact of changing the master line reactive power flow, in (\%) of its value for the power system without installing IPFC device, on the power system losses (active and reactive) and the IPFC common bus voltage.

(A)

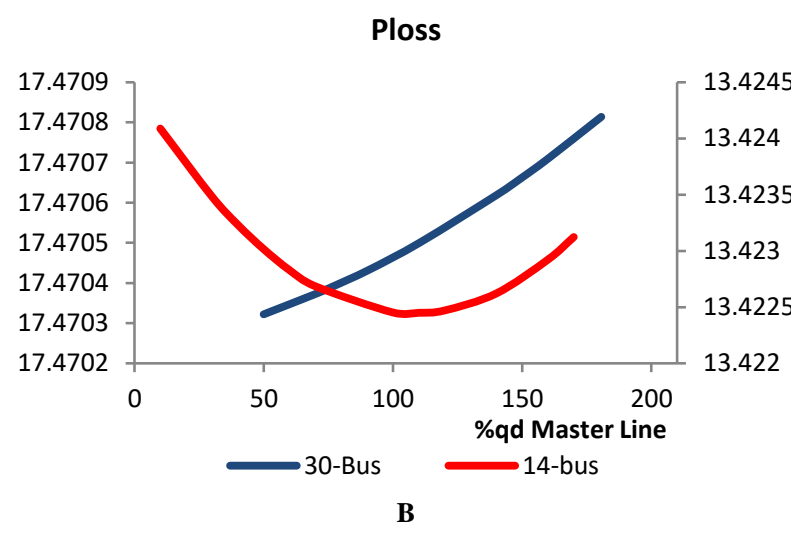

Qloss

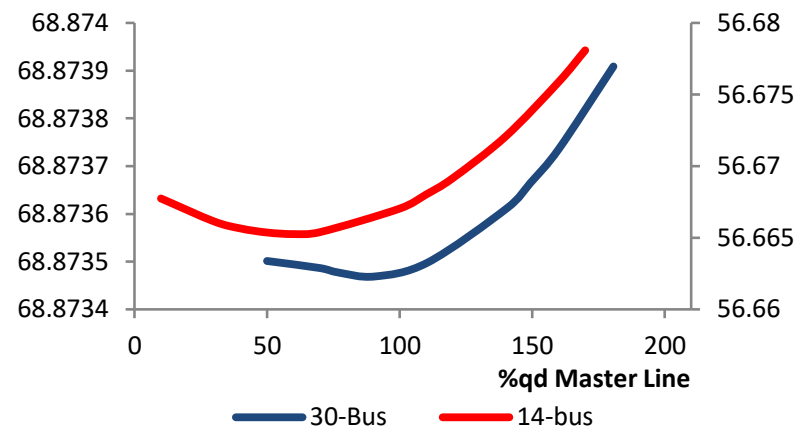

(C)

\section{V common bus}

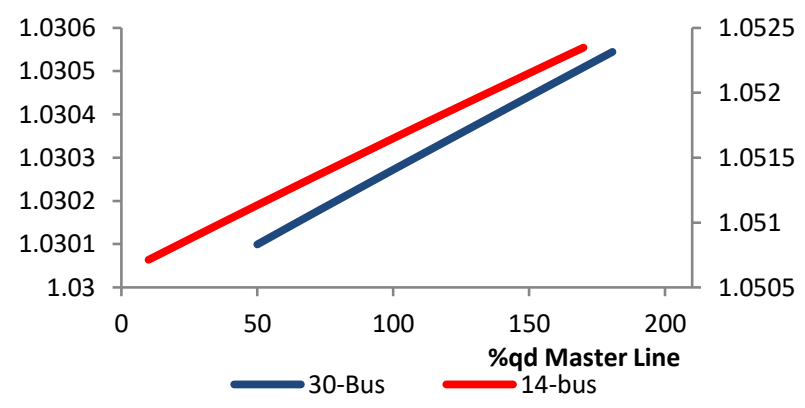

Fig. 10: Case 2 Impact of Changing Master Line Qd on A) Active Power Loss (Ploss), B) Reactive Power Loss (Qloss) and C) IPFC Common Bus Voltage. 
Figs $11-\mathrm{a}, \mathrm{b}$ and $\mathrm{c}$ show the impact of changing the slave line reactive power flow, in (\%) of its value for the power system without installing IPFC device, on the power system losses (active and reactive) and the IPFC common bus voltage.

\section{(A)}

\section{Ploss}

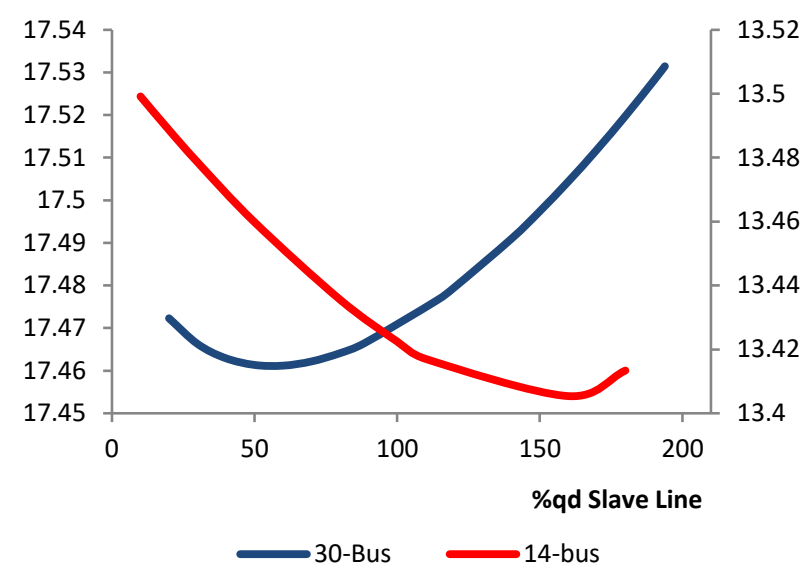

(B)

Qloss

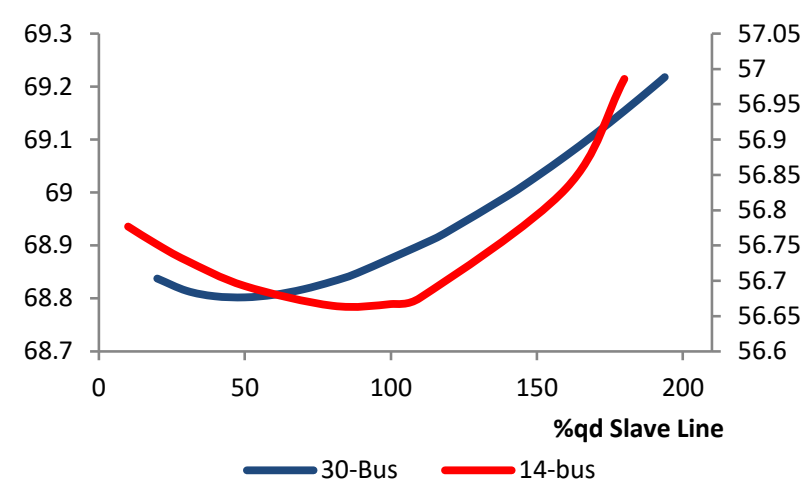

(C)

V common bus

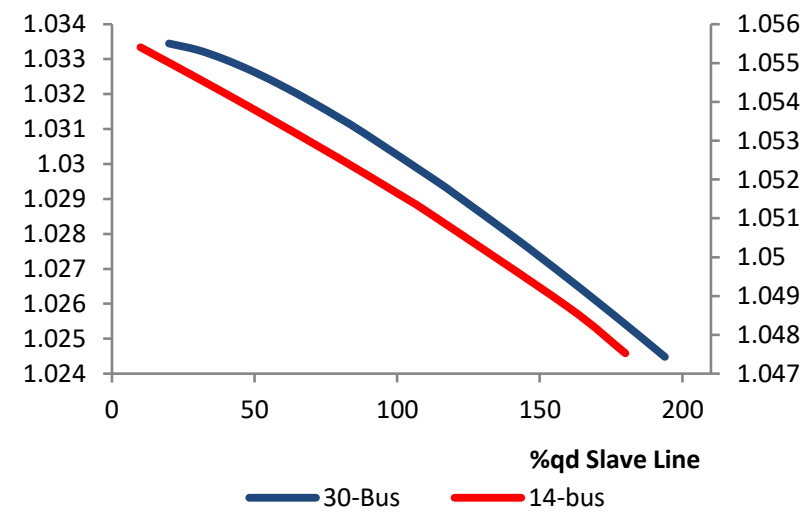

Fig. 11:Case 2 Impact of Changing Slave Line Qd on A) Active Power Loss (Ploss), B) Reactive Power Loss (Qloss) and C) IPFC Common Bus Voltage.

Case 2 results shows that the overall behaviour of the system equipped by IPFC device has recorded approximately similar results with different power systems. Some results like that shown in Figs 9-a and 10-a were indicating difference data curves between 30-Bus and 14-Bus systems. In Fig. 11-a, however similar data profile has been noticed, the $\mathrm{x}$-axis data range were different.

\subsection{Case 3}

Figs 12, 13 and 14 show the impact of changing the control parameters (master line $\mathrm{pd}$, qd and slave line $\mathrm{qd}$ ) on the power system losses (active and reactive) and the IPFC common bus voltage. This case results are very similar for both 30 -Bus and 14-Bus systems.

(A)

Ploss

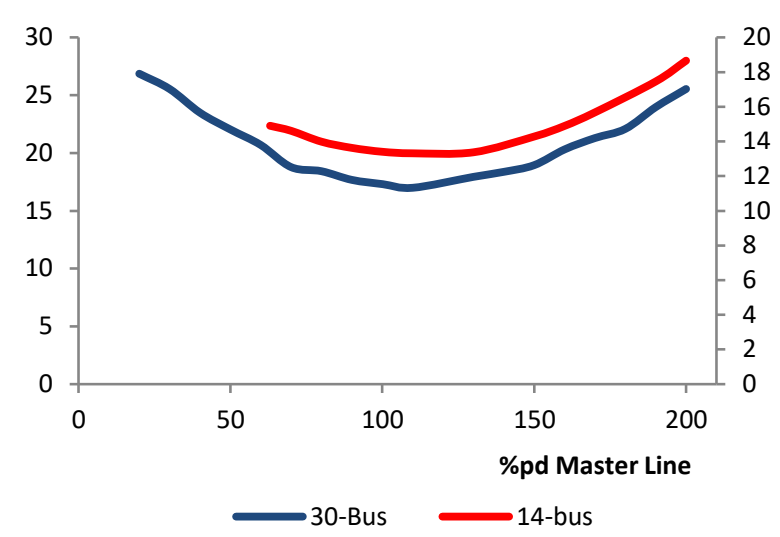

(B)

Qloss

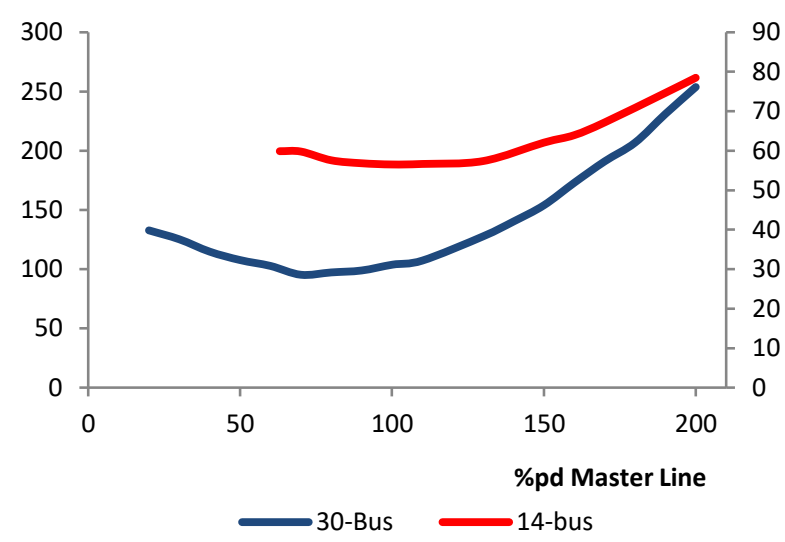

(C)

V common bus

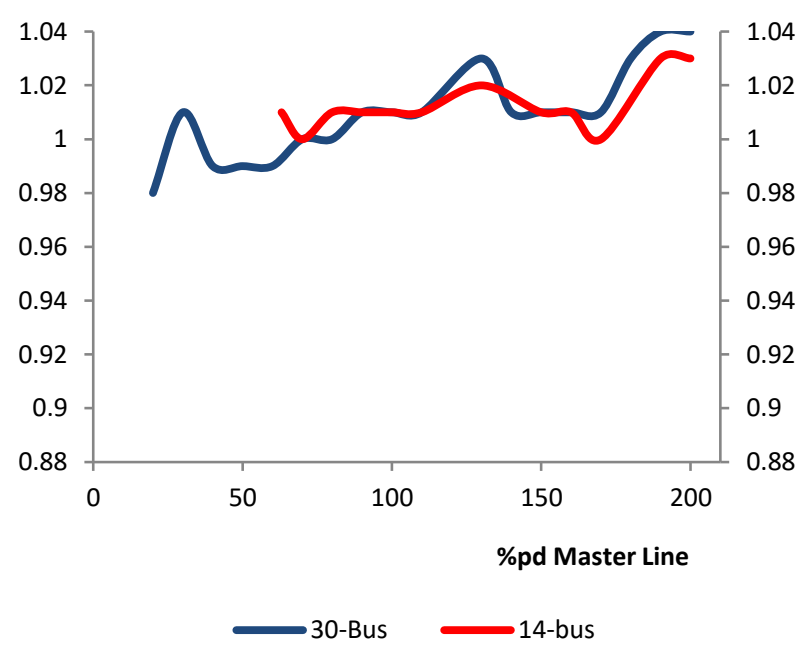

Fig. 12:Case 3 Impact of Changing Master Line Pd on A) Active Power Loss (Ploss), B) Reactive Power Loss (Qloss) and C) IPFC Common Bus Voltage. 
(A)

Ploss

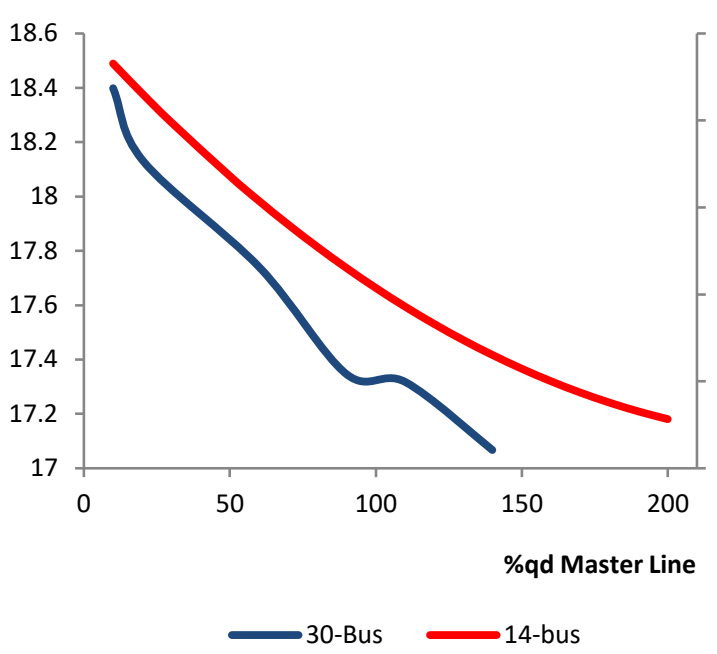

(B)

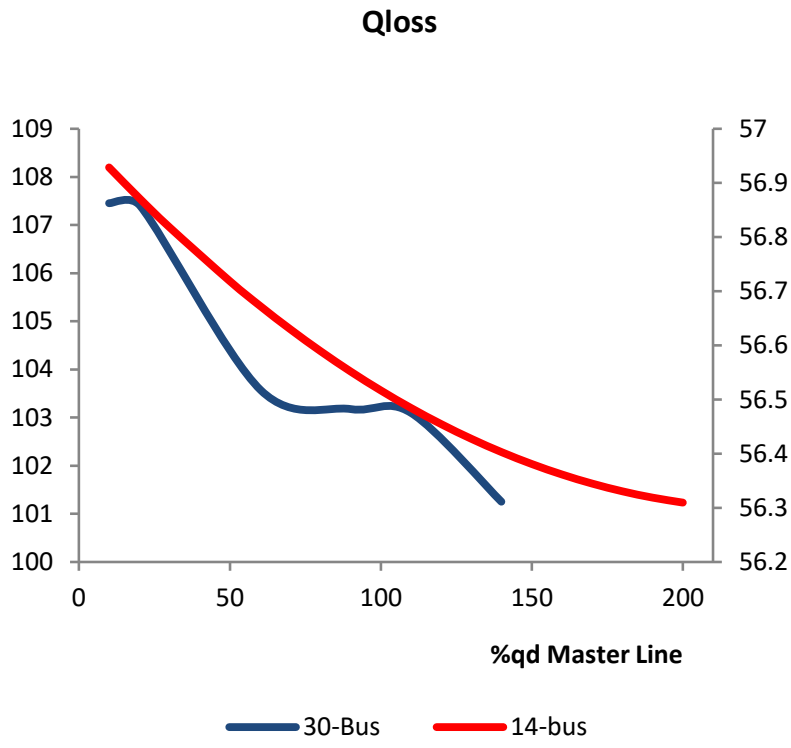

(C)

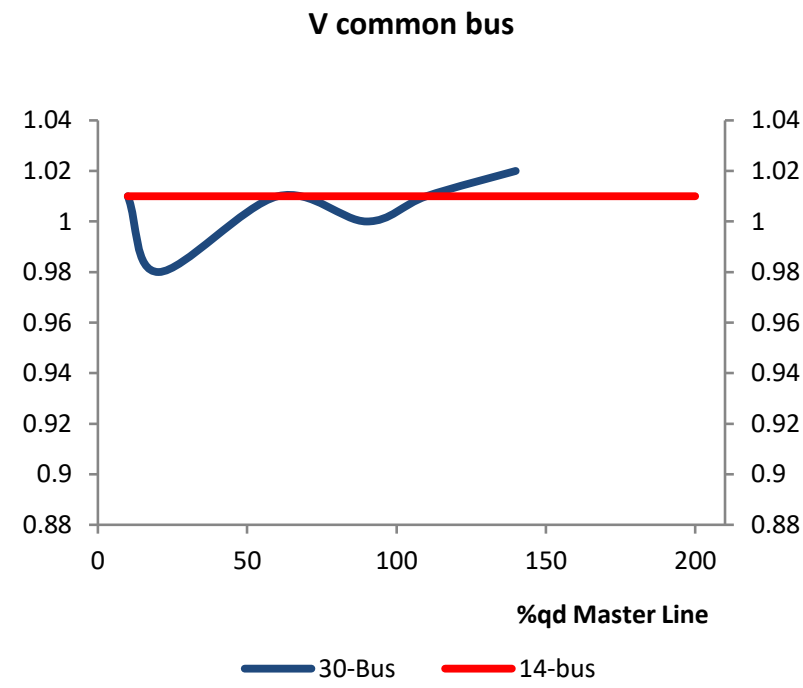

Fig. 13:Case 3 Impact of Changing Master Line Qd on A) Active Power Loss (Ploss), B) Reactive Power Loss (Qloss) and C) IPFC Common Bus Voltage.
(A)

Ploss

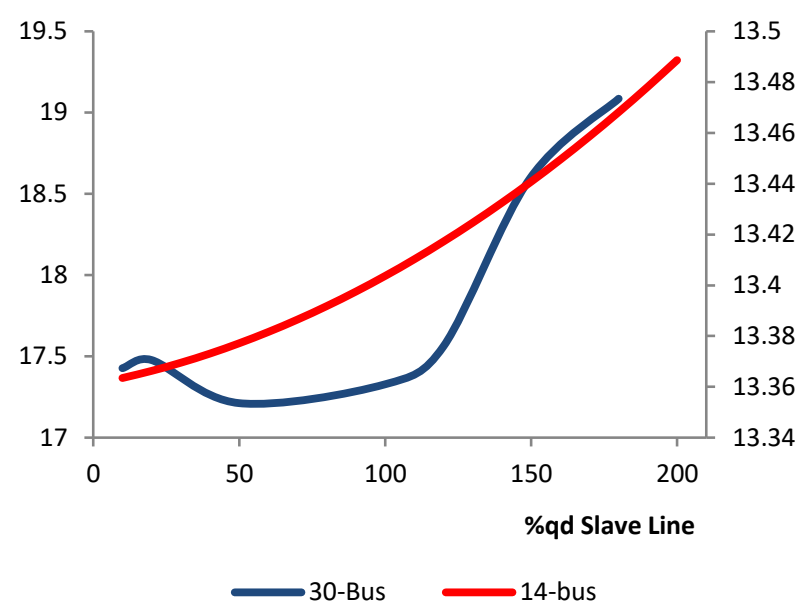

(B)

Qloss

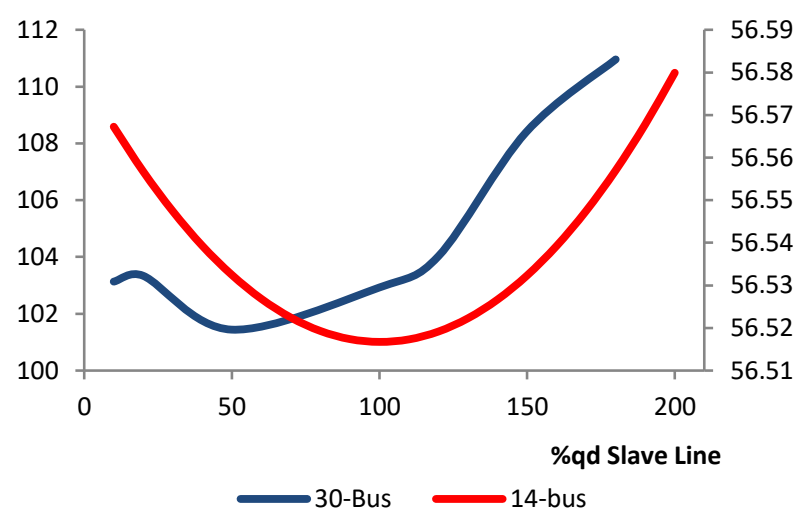

(C)

$\mathrm{V}$ common bus

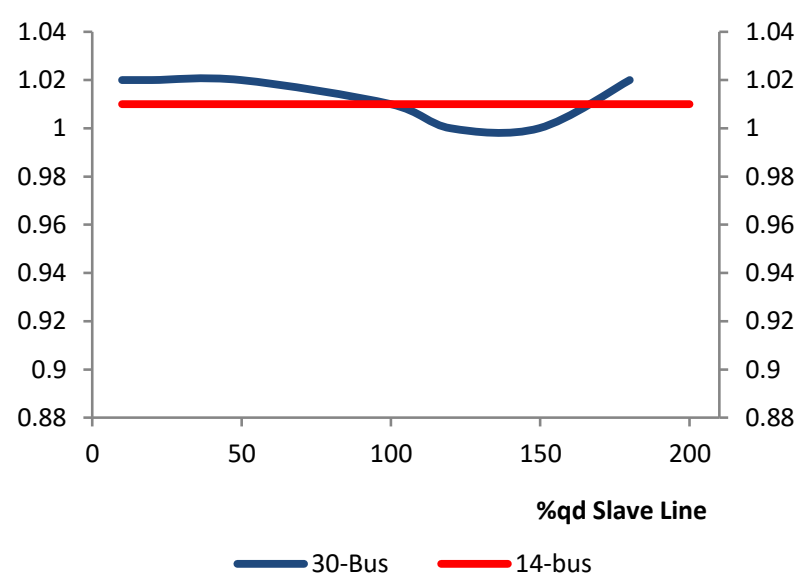

Fig. 14:Case 3 Impact of Changing Slave Line Qd on A) Active Power Loss (Ploss), B) Reactive Power Loss (Qloss) and C) IPFC Common Bus Voltage.

The results for cases 1,2 and 3 might be very helpful to draw a known scenario for the behaviour of the power system equipped with IPFC device in each case, but actually it is very clear that at general the performance of the IPFC device on either power losses or common bus voltage is a part of sinusoidal wave except at the case of that the common bus is a voltage control bus at which the common bus voltage is approximately constant. That behaviour is 
matching the theoretical principle of operation which emphasize that the driven model is verified.

\section{Conclusion}

This paper has tackled the interline power flow controller performance in IEEE 30-Bus and 14-Bus systems. It is distinguished than other IPFC performance analysis research papers by choosing different system configurations as case studies to provide the variety in addition to studying a profile of data over change in the parameters. It can be concluded that, it is possible to define a known scenarios for the IPFC performance in power systems. At general the active and reactive power losses has changed as a part of sinusoidal wave but new study is important to be applied for any new system or system configuration changes to define the range of applicable results. The study has matched the theoretical principle of operation and verified the mathematical model.

\section{References}

[1] Pavlos S. Georgilakis, Peter G. Vernados, "Flexible AC Transmission System Controllers: An Evaluation", Materials Science Forum Vol. 670 (2011) pp 399406 (C) (2011) Trans Tech Publications, Switzerland https://doi.org/10.4028/www.scientific.net/MSF.670.399.

[2] S. Sankar, S. Ramareddy, "Simulation of Closed Loop Controlled IPFC System", IJCSNS International Journal of Computer Science and Network Security, VOL.7 No.6, Jun. 2007.

[3] P. Asare et al, "An Overview of Flexible AC Transmission Systems", ECE Technical Reports, Paper 205 , http://docs.lib.purdue.edu/ecetr/205, 1994

[4] G. Radhakrishnan, dr. V. Gopalakrishnan, "Application of an Interline Power Flow Controller AS AGC”, JATIT and LLS, Vol. 54, Issue 3, 2013

[5] A.V.NareshBabu, S.Sivanagaraju, Ch.Padmanabharaju and T.Ramana, " Multi-Line Power Flow Control using Interline Power Flow Controller (IPFC) in Power Transmission Systems", International Journal of Electrical Power and Energy Systems Engineering 3:3 2010

[6] A.V.NareshBabu, S.Sivanagaraju, Ch.Padmanabharaju and T.Ramana, " Mathematical Modeling, Analysis and Effects of Interline Power Flow Control (IPFC) Parameters in Power Flow Study", Proc. of 4th IEEE- India Int. Conf. on Power Electronics, New Delhi, India, Jan. 2011
[7] Sasan Salem and V. K. Sood, " Simulation and Controller Design of an Interline Power Flow Controller in EMTP RV", International Conference on Power Systems Transients (IPST'07) in Lyon, France on June 4-7, 2007

[8] R. Strzelecki, G. Benysek, "Interline Power Flow Controller - New Concept of the Connection in Multiline Transmission Systems", TechnicnaElektrodinamika Journal, No. 4, 6366, 2010.

[9] S. Jilledi, "Comparison of Multi-Line Power Flow Control Using Unified Power Flow Controller (UPFC) and Interline Power Flow Controller (IPFC) in Power Transmission Systems", International Journal of Engineering Science and Technology (IJEST), Vol. 3 No. 4 Apr. 2011.

[10] Nabil A. Hussein, Ayman A. Eisa, Safey A. Shehata and EssamEddin M. Rashad, "Impact of Changing Inter-Line Power Flow Controller Parameters on the Power System", Proceeding of the International Middle East Power Systems Conference (MEPCON'14), Ain Shams Univ., Cairo, Egypt, December 23-25, 2014, Paper ID 176.

[11] N. Santos, O. Dias, V. Pires, "Use of an Interline Power Flow Controller Model for Power Flow Analysis", Energy Procedia, 14, 2096-2101, 2012. https://doi.org/10.1016/j.egypro.2011.12.1213.

[12] N. JAIN, "IFTIPFC: an interactive functional toolkit related to Interline Power Flow Controller", IPASJ International Journal of Electrical Engineering (IIJEE), Vol. 2, No. 7, Jul. 2014.

[13] A. Benslimane and C. Benachiba, "Power Quality Enhancement Using the Interline Power Flow Controller", International Journal of Power Electronics and Drive System (IJPEDS), Vol. 6, No. 3, 415-422, Sep. 2015

[14] A. Mishra, V. Gundavarapu, "Contingency management of power system with Interline Power Flow Controller using Real Power Performance Index and Line Stability Index", Ain Shams Engineering Journal, Vol. 7, 209-222, 2016.https://doi.org/10.1016/j.asej.2015.11.004.

[15] K. Ravishanker, P. Reddy, "Performance Analysis of Interline Power Flow Controller for Practical Power System"' International Journal of Scientific Engineering and Technology Research, Vol. 5, No. 6, 1088-1094, Mar. 2016.

[16] B. Karthik and S. Chandrasekar, "Modeling of IPFC for Power Flow control in 3-Phase line -Further Aspects and its Limitations", International Journal of Computer and Electrical Engineering, Vol.4, Issue.2, April 2012

[17] N.G Hingorani, G. Gyugyi Lazlo, "Understanding FACTS: Concepts \& technology of flexible AC Transmission Systems", ISBN 0-7803-3455-8. IEEE Order No. PC5713.

[18] Jinquan Zhao, Hsiao-Dong Chiang, Hua Li, Ping Ju, "On PV-PQ Bus Type Switching Logic In Power Flow Computation", 16th PSCC, Glasgow, Scotland, July 14-18, 2008. 